Authors have nothing to disclose with regard to commercial support.

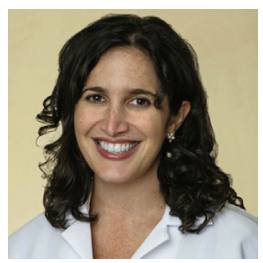

\section{AN ETHICAL JUSTIFICATION FOR THE WITHDRAWAL OF VENTRICULAR ASSIST DEVICES}

\section{To the Editor:}

In their recent article, Entwistle and Fenton ${ }^{1}$ correctly note that a patient who is physiologically well after ventricular assist device (VAD) placement but who experiences extreme existential distress presents ethical and legal problems. They conclude that because a patient with a VAD does not have a terminal illness, removal of the device under any circumstances is "more akin to 'killing' than 'allowing to die."'

The suggestion that disconnecting a VAD is the same as killing a patient is troubling. There exists a morally (and legally) significant difference between killing patients and allowing them to die naturally of underlying disease. The crux of the authors' distinction between the 2 rests on the new physiologic condition of aortic insufficiency created when a VAD is inserted and subsequently turned off. In doing this, according to the authors, a new "lethal condition" has been created and therefore, meets the definition of killing rather than letting a patient die of his or her pre-existing condition. However, VADs are placed in patients with end-stage heart failure who, without intervention, would be considered terminally ill. The physiologic changes created by the VAD do not change the fact that the patient has an underlying terminal illness, and without the life-sustaining support of the VAD, would die in a short period of time. Although aortic insufficiency caused by the deactivation of a VAD may hasten death, a patient is ultimately dying of his or her underlying heart failure. The aortic insufficiency is a very narrow, technical view of the cause of death and should not negate the ethical justification for removing a patient's VAD.

Additionally, Entwistle and Fenton ${ }^{1}$ suggest that a patient could avoid asking for physician assistance by simply disconnecting a VAD's power supply at home to end his or

\footnotetext{
The Editor welcomes submissions for possible publication in the Letters to the Editor section that consist of commentary on an article published in the Journal or other relevant issues. Authors should: • Include no more than 500 words of text, three authors, and five references. • Type with double-spacing. • See http://jtcs.ctsnetjournals.org/ misc/ifora.shtml for detailed submission instructions. • Submit the letter electronically via jtcvs.editorialmanager.com. Letters commenting on an article published in the JTCVS will be considered if they are received within 6 weeks of the time the article was published. Authors of the article being commented on will be given an opportunity of offer a timely response ( 2 weeks) to the letter. Authors of letters will be notified that the letter has been received. Unpublished letters cannot be returned.
}

her life. This is unacceptable because the symptoms caused by cessation of VAD support must be managed carefully. The authors say a prescription for anxiolytics or narcotics to "ease the pain or anxiety associated with this process" is reasonable ${ }^{1}$; however, the doses that would be prescribed to an outpatient are unlikely to adequately treat symptoms such as dyspnea and chest pain that occur when the machine stops. It is unethical to force patients to suffer at the end of life without appropriate palliative care or medical supervision.

We certainly do not suggest that the discontinuation of a VAD is permissible in any kind of circumstance. However, it is possible that despite best medical efforts and emotional support, patients may find their lives so severely limited that they would reject the ongoing life support provided by a VAD. In fact, a recent study showed that 6 months after successful VAD implantation, 20\% would not agree to VAD placement if they could make the decision again. ${ }^{2}$ Under such convincing circumstances, physician compliance and supervision with removal of life-sustaining VAD therapy should be considered ethically justifiable.

Katherine Fischkoff, MD, MPA

Shunichi Nakagawa, $M D^{b}$

David Blitzer, $M D^{c}$

Yoshifuma Naka, MD, PhD

${ }^{a}$ Division of Clinical Ethics

Department of Surgery and Critical Care

${ }^{b}$ Adult Palliative Care

Department of Medicine

${ }^{c}$ Division of Cardiothoracic Surgery

Columbia University College of Physicians and Surgeons

New York, $N Y$

\section{References}

1. Entwistle JWC, Fenton KN. Rethinking the ethics of ventricular assist device withdrawal. J Thorac Cardiovasc Surg. 2019;159:1329-33.

2. Unai S, Yamane K, Tanaka D, Cook G, Hirose H, Cavarocchi NC, et al. Quality of life and mid-term survival of patients bridged with extracorporeal membrane oxygenation to left ventricular assist device. ASAIO J. 2017;63:273-8.

\section{https://doi.org/10.1016/j.jtcvs.2020.01.075}

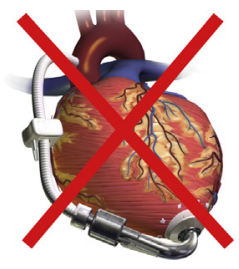

\section{REPLY: DEATH IS SAD, BUT NO ONE'S BAD TO STOP A VAD \\ Reply to the Editor:}

Fischkoff, Nakagawa, and Blitzer ${ }^{1}$ criticize Entwistle and Fenton's article $^{2}$ on several grounds. I believe their criticisms are valid. The patient does indeed have a terminal condition: his underlying heart failure. Entwistle and Fenton ${ }^{2}$ rely on Sulmasy's definition of killing, but they offer no justification for adopting a single, narrow 
Author has nothing to disclose with regard to commercial support.

viewpoint. A broader discussion of what constitutes killing can be found in Beauchamp and Childress's classic treatise Principles of Biomedical Ethics, ${ }^{3}$ which makes it clear that the meaning of terms such as killing and letting die is highly controversial: "The meanings of 'killing' and 'letting die' are vague and inherently contestable. Attempts to refine their meanings likely will produce controversy without closure." 3 Other definitions could lead to a conclusion that discontinuing a continuous flow ventricular assist device (cfVAD) is less like killing and more like letting die.

Fischkoff and colleagues ${ }^{1}$ suggest that the presence of acute severe aortic insufficiency equivalent physiology (AI-EP) when a cfVAD is disconnected does not render the act unethical. The critical ethical issue in the case of cfVAD withdrawal is not the new lethal physiologic condition of AI-EP, but rather it is the presence of a voluntary and fully informed request for discontinuation of an unwanted medical device by a terminally ill patient with decision-making capacity. In this case, the terminally ill patient is receiving life support with a cfVAD, so discontinuing the device is neither physician-assisted suicide nor voluntary active euthanasia-it is letting die, equivalent to disconnecting a ventilator from a ventilator-dependent patient.

Neither Entwistle and Fenton ${ }^{2}$ nor Fischkoff and colleagues $^{2}$ mention an important alternative possibility for decommissioning a cfVAD, namely, blocking retrograde flow through the device. Transcutaneous insertion of an obstructive plug in the conduit ${ }^{4}$ or ligation of the conduit through a small thoracotomy incision ${ }^{5}$ can prevent backflow, placing the patient in the same clinical situation he was in before the cfVAD was implanted, thus allowing him to die as a result of heart failure, as he wishes, without AI-EP. Obstructing backflow obviates all the ethical issues Entwistle and Fenton ${ }^{2}$ raise.

Robert M. Sade, $M D$ Institute of Human Values in Health Care Division of Cardiothoracic Surgery Department of Surgery Medical University of South Carolina Charleston, SC

\section{References}

1. Fischkoff K, Nakagawa S, Blitzer D. An ethical justification for the withdrawal of ventricular assist devices. J Thorac Cardiovasc Surg. 2020;160:e5.

2. Entwistle JWC, Fenton KN. Rethinking the ethics of ventricular assist device withdrawal. J Thorac Cardiovasc Surg. 2019;159:1329-33.

3. Beauchamp TL, Childress JF. Killing and letting die, Principles of Biomedical Ethics. 7th edition. New York: Oxford University Press; 2009:174-9.
4. Soon JL, Tan JL, Lim CP, Tan TE, Tan SY, Kerk KL, et al. Percutaneous decommissioning of left ventricular assist device. Heart Lung Circ. 2018;27: 853-5.

5. Cheung A, Bashir J, Kaan A, Kealy J, Moss R, Shayan H. Minimally invasive, off-pump explant of a continuous-flow left ventricular assist device. J Heart Lung Transplant. 2010;29:808-10.

https://doi.org/10.1016/j.jtcvs.2020.02.016

\section{REPLY: THERE ARE LIMITS TO AUTONOMY}

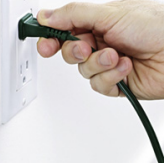

\section{Reply to the Editor:}

We appreciate the concerns of Fischkoff and colleagues ${ }^{1}$ regarding the ethics of withdrawal of left ventricular assist device (LVAD) support, and we agree with 2 important points they have made: first, that it would be "unethical to force patients to suffer at the end of life without appropriate palliative care," and second, that the discontinuation of VAD support is not permissible in all circumstances. We do wish to make a few comments.

We agree with the established consensus that a patient with capacity can refuse medical therapy at any time. In our manuscript, we have attempted to address the question of how this can best be applied to a patient with a VAD facing existential distress and whether there were other ethical issues involved. The central point of our argument is not that the LVAD creates a new physiology and therefore discontinuation is wrong. Rather, we argue that it is that it is time to rethink the limits of autonomy as related to LVAD withdrawal.

We believe that the issue is more complex than just a patient refusing care. This refusal places a duty on the caregiver to disconnect the device, unlike other conditions in which a patient no longer wants treatment. Further, this is an action that the patient or family can take themselves, without invoking the actions of the medical profession. Finally, the physiology is altered, so that discontinuation is not returning them to a condition that was present before the operation. Unlike renal failure, where cessation of dialysis returns them to the same state as before dialysis was started, discontinuation of LVAD support places them in a position that is worse than before therapy. One of the key arguments in the refusal or withdrawal of care is that we are letting nature take its course. In this case, the natural physiology has been altered in a way that the acute aortic insufficiency will be the mode of death, not heart failure.

Fischkoff and colleagues include patients with LVAD among the terminally ill, but these patients do not meet legal criteria for terminal illness (life expectancy of less than 6 months, in most states). The data on LVAD clearly show that heart failure on LVAD therapy is not a terminal disease or a lethal condition. In the absence of a complication, survival on LVAD support is measured in years, not months. Until a complication happens, a patient with a LVAD is no different than any other patient who is at greater than 